\title{
Crop growth monitoring through Sentinel and Landsat data based NDVI time-series
}

\author{
M.S. Boori ${ }^{1,2,4}$, K. Choudhary ${ }^{1,3,4}$, A.V. Kupriyanov ${ }^{1,5}$ \\ ${ }^{1}$ Samara National Research University, Moskovskoye Shosse 34, 443086, Samara, Russia, \\ ${ }^{2}$ American Sentinel University, Colorado, USA, \\ ${ }^{3}$ The Hong Kong Polytechnic University, Kowloon, Hong Kong, \\ ${ }^{4}$ University of Rennes 2, Rennes, France, \\ 5 IPSI RAS - Branch of the FSRC “Crystallography and Photonics” RAS, \\ Molodogvardeyskaya 151, 443001, Samara, Russia
}

\begin{abstract}
Crop growth monitoring is an important phenomenon for agriculture classification, yield estimation, agriculture field management, improve productivity, irrigation, fertilizer management, sustainable agricultural development, food security and to understand how environment and climate change effect on crops especially in Russia as it has a large and diverse agricultural production. In this study, we assimilated monthly crop phenology from January to December 2018 by using the NDVI time series derived from moderate to high Spatio-temporal resolution Sentinel and Landsat data in cropland field at Samara airport area, Russia. The results support the potential of Sentinel and Landsat data derived NDVI time series for accurate crop phenological monitoring with all crop growth stages such as active tillering, jointing, maturity and harvesting according to crop calendar with reasonable thematic accuracy. This satellite data generated NDVI based work has great potential to provide valuable support for assessing crop growth status and the above-mentioned objectives with sustainable agriculture development.

Keywords: crop phenology, NDVI time-series, Sentinel-2 \& Landsat, remote sensing.

Citation: Boori MS, Choudhary K, Kupriyanov AV. Crop growth monitoring through Sentinel and Landsat data based NDVI time-series. Computer Optics 2020; 44(3): 409-419. DOI: 10.18287/2412-6179-CO-635.

Acknowledgments: This work was partially supported by the Ministry of education and science of the Russian Federation in the framework of the implementation of the Program of increasing the competitiveness of Samara University among the world's leading scientific and educational centers for 2013-2020 years; by the Russian Foundation for Basic Research grants (\# 15-29-03823, \# 16-41-630761, \# 17-01-00972, \# 18-37-00418), in the framework of the state task \#0026-20180102 "Optoinformation technologies for obtaining and processing hyperspectral data".
\end{abstract}

\section{Introduction}

Continuously increasing the world population, increase the presser on agriculture land and production to compete for the demand. Detailed and accurate information about crop growth is very important for a specific region for a range of scientific and development purposes with environmental consequences (Leff et al., 2004, UN, 2015). Generally, crop growth monitoring use for agriculture classification, yield estimation, agriculture field management, improve productivity, irrigation, fertilizer management, sustainable agricultural development, food security and to understand how environment and climate change effect on crops $[1,2]$. A crop growth study could quantify crop growth physiological development and yield, with interactions among environmental characteristics such as soil, weather, water, etc. Normally crops have three major growth stage (1) vegetative stage, including germination, seedling, tillering and jointing, (2) reproductive stage, including booting, heading and flowering, (3) maturation stage show mature plant with grains. During the crop growth monitoring, farming techniques and management is also very important from the beginning to the mature stage for the decision-making authorities to decide on the issues of food security especially in extreme weather conditions such as famine or drought. In Russian context agriculture, land use is going under dramatic changes due to extreme weather conditions, socioeconomic activities and human interference in natural resources as well as capitalism and rural depopulation. This is reducing the overall willingness and interest in farming or agriculture in Russia as extreme weather conditions repeat in terms of frequency and magnitude. This highlights the urgent call for crop growth monitoring study throughout the growing season to increase crop resilience and reduce production risks [3].

Satellite remote sensing has been widely used in the agriculture field for crop mapping and monitoring from the beginning of launching Landsat series in 1972. It's better than conventional methods such as ground surveys or questionnaires, in terms of spatial-temporal resolution, coverage area, and less manual labor. Satellite remote sensing-based crop growth monitoring has also some limitations in terms of low spatial-temporal resolution and 
weather effects with less frequency of data. Still, accurate crop growth monitoring, yield estimation, and forecast have been challenging tasks at the individual field level [4]. As well, temporally sensitive applications such as timely detection of production risks from disease or severe weather may be missed with these weekly products. However, still, satellite data derived NDVI time series is the best option for crop growth or phenological extraction with a spatial-temporal resolution during the crop growth period [5].

There are several methods for crop phenology identification but the most commonly used method is Normalized Difference Vegetation Index (NDVI) threshold, which was used by many researchers $[6,7]$. Even for the last long time, several national and international agencies in many countries use NDVI as an indicator of crop condition. NDVI is a strong indicator of crop development due to the absorption of red wavelength energy in the electromagnetic spectrum by plant chlorophyll and reflection of infrared (IR) energy by plant cell structure. So NDVI can fully correlate with biomass by IR reflectance and later on crop development and help to identify changes in crop production. Earlier many studies detect different crop stages during crop growth period with the help of NDVI time-series such as tillering, heading and harvesting [8]. When NDVI values changes from negative to positive direction, its show initial crop growth stage like early phase of green leaf, peak NDVI values relate to highest crop growth stage and once NDVI time series curve shift from positive to negative, its determine full mature stage of crop or start harvesting [9].

Crop growth monitoring is also essential to know the crop phenology since phenological information affects crop matter distribution during the growing stages [10, 11]. Phenology is an innate image of crop growth, which reflects from crop intermittent biological changes affected by the climate and other environmental conditions [12]. However, few studies have optimized crop growth simulation regarding the development of crop phenology based on the NDVI time series. Satellite data derived NDVI is also a sensitive indicator for canopy background such as soil properties [13]. That's why since last long time, NDVI based biophysical parameters have been used as they are significant for different crop growth stages and can easily detect from remote sensing data. [14] used the NDVI time series for rice crop growth monitoring. [15] also demonstrate that NDVI based crop yield estimation accuracy depends on the different phenological stages, temporal frequency, and spatial scale.

However, this study gives attention to identify all growth stages from the beginning of germination/seeding to fully mature plant with grains for better sustainable development of agriculture and to filling literature gaps of earlier studies. This research work was employed Sentinel-2B and Landsat 8 (OLI) data for monthly NDVI time series based crop growth or phenology study in Samara Airport area, Russia. This paper organized as follows:
Section 1 introduction about the study; Section 2 describes the study area; Section 3 presents material and methodological aspects; Section 4 is highlights the results and main findings; Section 5 discussion and finally conclusions are given in Section 6.

\section{Study area}

We choose the agriculture land of Samara Airport area in Russia as a study area. Samara region is situated in the South-East of the Eastern European Plain in the middle flow of the greatest European river of Volga (fig. 1.). Geographical coordinates are $53^{\circ} 12^{\prime} 10^{\prime \prime} \mathrm{N}$, $50^{\circ} 08^{\prime} 27^{\prime \prime} \mathrm{E}$ (fig. 1). The region occupies an area of 53600 square kilometers $(0.31 \%$ of the territory of Russia) and forms a part of the Volga Federal District. The land within the city boundaries covers 46,597 hectares $(115,140$ acres $)$ with population: $1,164,685$ (2010 Census); 1,157,880 (2002 Census); 1,254,460 (1989 Census). Formerly a closed city, Samara is now a large and important social, political, economic, industrial, and cultural center in European Russia. It has a continental climate characterized by hot summers and cold winters. Winters are very cool with high snowfall; the average temperature is around $5.7^{\circ} \mathrm{C}$. Rainfall is widely distributed throughout the year, falls in summer (April to September) usually in the form of a thundershower. The winter (December to February) rain as a snowfall that impacts positively on winter crops. The major crops grown in the study area are grain, sunflower, sugar beets, potatoes, wheat, maize, mustard, onion, etc. whereas some of the fruits are grown as cash crops. This study area situated within Russia's black soil (Chernozem) grain belt, known as highly fertile land. Fieldwork was held during the summer of 2018 and performed extensive interviews with district administrators, farm managers and other members of the population. Remote sensing was used to advance our understanding of ongoing agricultural changes in the region.

\section{Material and methodology}

\subsection{Data}

For monthly crop growth monitoring, we were acquired 12 Sentinel 2B and Landsat 8 OLI images respectively from January to December 2018 for the study area from the united states geological survey (USGS) website. We used band 8, 4, 3 and 5, 4, 3 band combinations for RGB from Sentinel 2B bands at $10 \mathrm{~m}$ resolution and Landsat 8 OLI at $30 \mathrm{~m}$ resolution respectively (table 1). This help for crop cover visual assessment of the field during cloud or shadow cover situation [16]. NDVI products from both satellite data were employed to extract crop phenology information.

Sentinel 2 is an earth observation mission launched on 07 March 2017 from European Space Agency (ESA). The mission supports a broad range of services and applications such as agricultural monitoring, emergency management, and land cover classification or water quality. 
Sentinels 2 is better than SPOT and LANDSAT in terms of resolution and repeat the cycle as it's have 10 to $60 \mathrm{~m}$ spatial resolution with $290 \mathrm{~km}$ swath, 13 spectral bands and 10 days repeat the cycle in Multispectral Imager (MSI) sensor (table 1). Landsat 8 is an American Earth observation satellite launched on February 11, 2013. It is the eighth satellite in the Landsat program; the seventh to reach orbit successfully. Originally called the Landsat Data Continuity Mission, it is collaboration between NASA and the United States Geological Survey (USGS). Landsat 8 carries two sensors: (1) Operational Land Imager (OLI) and (2) the Thermal Infrared Sensor (TIRS). These two sensors provide seasonal coverage of the global landmass at a spatial resolution of 30 meters (visible, NIR, SWIR); 100 meters (thermal); and 15 meters (panchromatic). Landsat 8 has $185 \mathrm{~km}$ swath with 15 days revisit time (table 1).

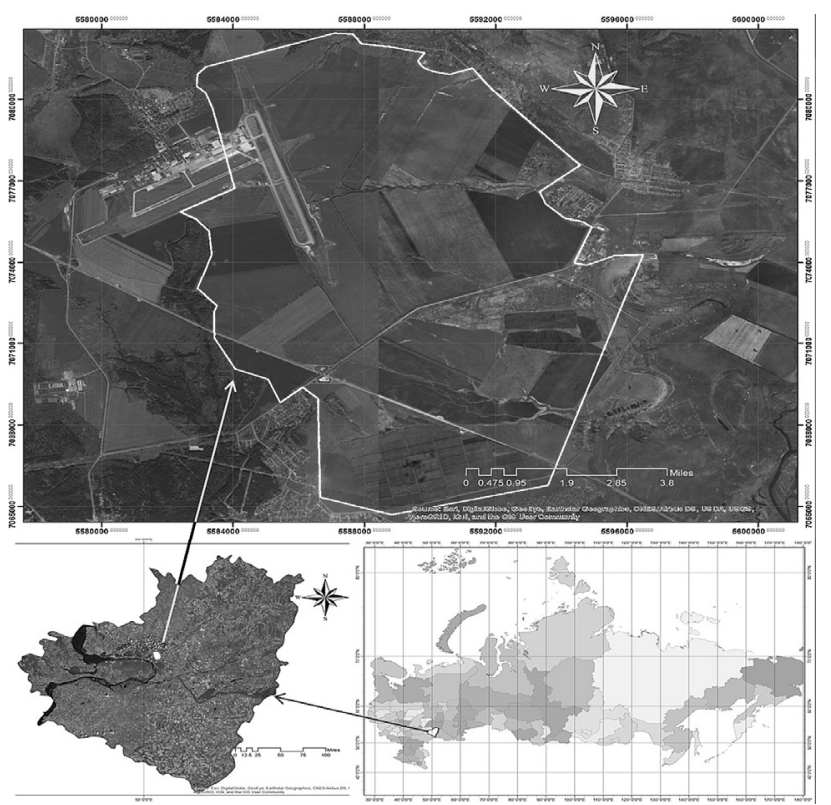

Fig. 1. Location of the study area

\subsection{Pre-processing}

Digital image processing work was done by the ArcGIS software. First, all satellite imageries were geometrically and radiometrically corrected, also remove all atmospheric errors such as dropouts as well as remove clouds by filtering. Image enhancement techniques like histogram equalization were also performed on each image for improving the quality of the image. Digital topographical maps at 1:50,000 scale, were used for image georeferencing for the thematic map and increase the accuracy of the overall assessment. At this stage, 25 points were selected as GCPs (Ground Control Point) in the study area. Different data sources used for the GCPpositioning were: digital topographic maps, GPS (Global Positioning System) coordinates and other data from the Google Earth system. After removing all errors, then derive the NDVI time series for crop growth and phenological profile from January to December 2018. All NDVI phenological maps were testified by ground-truthing with the help of hand-held GPS, during the study period.

Table. 1. Brief characteristics of Sentinel 2B (MSI) and Landsat 8 (OLI) sensors

\begin{tabular}{|c|c|c|}
\hline $\begin{array}{l}\text { Sentinel 2B - Multispec- } \\
\text { tral Imager (MSI) bands } \\
\text { (no.) }\end{array}$ & $\begin{array}{l}\text { Central } \\
\text { wavelength } \\
\quad(\mu \mathrm{m})\end{array}$ & $\begin{array}{l}\text { Spatial } \\
\text { resolution } \\
\quad(\mathrm{m})\end{array}$ \\
\hline $1-$ Coastal aerosol & 442.2 & 60 \\
\hline $2-$ Blue & 492.1 & 10 \\
\hline 3 - Green & 559.0 & 10 \\
\hline $4-$ Red & 664.9 & 10 \\
\hline $5-$ Vegetation red edge & 703.8 & 20 \\
\hline $6-$ Vegetation red edge & 739.1 & 20 \\
\hline 7 - Vegetation red edge & 779.7 & 20 \\
\hline $\begin{array}{l}8-\text { NIR } \\
8 \mathrm{~A}-\text { Narrow NIR }\end{array}$ & $\begin{array}{l}832.9 \\
864.0\end{array}$ & $\begin{array}{l}10 \\
20\end{array}$ \\
\hline 9 - Water vapor & 943.2 & 60 \\
\hline $\begin{array}{l}10-\text { SWIR - Cirrus } \\
11-\text { SWIR }\end{array}$ & $\begin{array}{l}1376.9 \\
1610.4\end{array}$ & $\begin{array}{l}60 \\
20\end{array}$ \\
\hline $12-$ SWIR & 2185.7 & 20 \\
\hline $\begin{array}{l}\text { Landsat } 8 \text { - Operational } \\
\text { Land Imager (OLI) bands }\end{array}$ & $\begin{array}{l}\text { Wavelength } \\
\qquad(\mu \mathrm{m})\end{array}$ & $\begin{array}{l}\text { Spatial } \\
\text { resolution } \\
(\mathrm{m})\end{array}$ \\
\hline 1 - Ultra Blue & $0.435-0.451$ & 30 \\
\hline $2-$ Blue & $0.452-0.512$ & 30 \\
\hline 3 - Green & $0.533-0.590$ & 30 \\
\hline $4-$ Red & $0.636-0.673$ & 30 \\
\hline $5-\mathrm{NIR}$ & $0.851-0.879$ & 30 \\
\hline $6-$ SWIR 1 & $1.566-1.651$ & 30 \\
\hline 7 - SWIR 2 & $2.107-2.294$ & 30 \\
\hline $\begin{array}{l}8 \text { - Panchromatic } \\
9 \text { - Cirrus }\end{array}$ & $\begin{array}{l}0.503-0.676 \\
1.363-1.384\end{array}$ & $\begin{array}{l}15 \\
30\end{array}$ \\
\hline $10-$ TIRS 1 & $10.60-11.19$ & $100 *(30)$ \\
\hline $11-$ TIRS 2 & $11.50-12.51$ & $100 *(30)$ \\
\hline \multicolumn{3}{|c|}{$\begin{array}{l}\text { * TIRS bands are acquired at } 100 \text { meter resolution, } \\
\text { but are resampled to } 30 \text { meter in delivered data product. }\end{array}$} \\
\hline
\end{tabular}

The remote sensing-based vegetation indices have been widely used by several researchers for various studies [17]. Stressed vegetation has a higher reflectance than healthy vegetation in the visible $(0.4-0.7 \mu \mathrm{m})$ region and lower reflectance in the near-infrared $(0.7-1.1 \mu \mathrm{m})$ region of the electromagnetic spectrum. Based on this characteristic of the spectral response of vegetation, Normalized Difference Vegetation Index (NDVI) was calculated. It is a very popular tool for mapping vegetation health or condition. Besides, it can be used for monitoring the continental land use and land cover, classification of vegetation and its phenology (Justice et al. 1985). It is also effective for monitoring desertification [17], drought [18], estimating net primary production of vegetation, crop growth conditions, yields, detecting weather impacts, etc. [15]. Following the streamlines in methodology, after image pre-processing, all satellite images were processed for the mapping of NDVI according to the following formula: 


$$
\mathrm{NDVI}=\frac{\mathrm{NIR}-\mathrm{Red}}{\mathrm{NIR}+\mathrm{Red}}
$$

The NDVI is an indicator of the vegetation greenness, which measuring by the difference between NIR and RED lights as NIR is strongly reflecting and red light is absorbed by plants. It always ranges from -1 to +1 . The negative values of NDVI (approaching -1 ) correspond to water or clouds. Values close to zero $(-0.1$ to 0.1$)$ generally correspond to barren areas of rock, sand, snow or urbanization. Lastly, low, positive values represent shrub and grassland (approximately 0.2 to 0.4 ), while high values indicate temperate, tropical rainforests or healthy and dense vegetation (values approaching 1) [19].

NDVI is a proxy for photosynthetic activity (fig. 2) and primary production from vegetation biomass and is a common index for monitoring vegetation health. High chlorophyll content (healthy plant) reflects a high amount of NIR in compare to green light and absorbs maximum red and blue lights. That's why plants look like green color. There is an example that how NDVI is calculated (fig. 2).

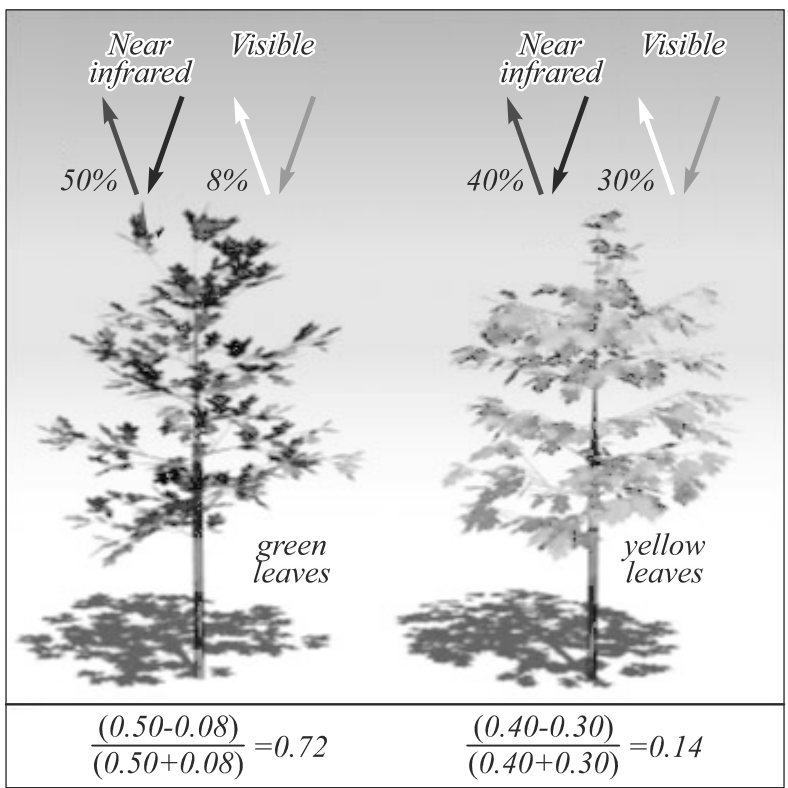

Fig. 2. Example of NDVI calculation (Source: Google)

High NDVI values represent healthier vegetation (green plants) and low NDVI values represent no vegetation, urbanization, clouds, snow or water body. Here NDVI was computed as the ratio of responses in near-infrared (NIR) and visible bands of the Sentinel 2B (MSI) and Landsat 8 (OLI) based sensors. NDVI was calculated from visible (band 4 Red) and near-infrared bands (band 8 NIR) combinations in ArcGIS software from Sentinel 2B and band number 4 (Red) and 8 (NIR) for Landsat data.

\section{$\underline{2.4 \text { Accuracy }}$}

Ground truth data and google earth images as they have high resolution with photographs were used for accuracy assessment and qualitative results. We have done field trips during the crop growing session from April to
September in mid of every month for the year of 2018. In the study area, 25 randomly distributed sampling plots were selected for field measurement with the help of a global positioning system (GPS). The results were reported in the form of a confusion matrix including the user's and producer's accuracy [20].

\section{Results \\ 3.1 Crop phenology and crop calendar}

Phenological profiles for all the crops extracted and mapped at 10 to 30-meter resolution with Sentinel 2B and Landsat. Both data allow us to estimate the area more precisely and accurately. The resulted NDVI time series represent seasonal trajectory in vegetation. All agriculture fields have low NDVI values from January to March but in April, its increase randomly. In the month of May-June all crops shows very high NDVI values with highest in July (fig. 3). From August maximum study area`s NDVI values start to reducing with low value in the month of September-October and lowest in the month of November-December (fig. 3). The resulted from the NDVI time series also show a distinct phenological peak (fig. 3) related to crop growth according to the crop calendar (table 2). Three crucial phenology stages, including tillering, heading and maturity were extracted from NDVI timeseries data to optimize the crop phenology development. As its peak value in July and harvest in September indicate that these fields are from summer crops. The trend of NDVI time series from January to December 2018 shows the variation of the entire year (fig. 3). All the profiles were plotted and checked against the crop calendar of the study area to identify the crop growth and phenology (table 2).

Table. 2. Crop phenology with crop calendar

\begin{tabular}{cc}
\hline Months & Phenology Phase \\
\hline January & Permanent snow cover \\
February & Snow cover \\
March & Start melting snow \\
April & Sowing \& Emergence \\
May & Tillering \& Hibernation \\
June & Jointing \& Booting \\
July & Flowering \\
August & Ripening \\
September & Harvesting \\
October & Harvesting \\
November & Start snow cover \\
December & Start permanent snow cover \\
\hline
\end{tabular}

Table 2 represents general crop phenology with crop calendar in the study area. We find highest average NDVI value in July (0.45) and loweast from January to March (0.01). In the study area maximum NDVI values reach up to 0.84 in summer session (May to Septemebr), which represent very healthy agricluture due to highly fertile soil (black) and fine weather condition (fig. 3). That's why this area have high production rate. NDVI values increase rapidly from April, (sowing \& emergence) to May (tillering \& hibernation) and its maximum increase rate was in June 
(jointing \& booting) and then remained stable July (initial heading, filling \& flowering). After that NDVI decline slowly and its decrease trend in August show ripening and maturity and decreased more significantly in September and October represent harvesting stage (table 2). Three stages of crop growth have been identified by the field work (1) Canopy closure, or the presence of visible bare soil. This stage presents in beginning of plant, generally till beginning of April in the study area, (2) Stem extension or plant growth stage, this stage shows growth of plants (stem, leaf, flowering) and soil are stop to visible. Its shows lowest to highest NDVI values and genearlly from May to August months in the study area, (3) Visible ears, this is the eand of growth stage. Only full mature plants are in this stage so heading and ripening is present without soil visibility so only ears are visible. It's the time of harvest and generally in Septemebr-October (fig. $3 \&$ table 3 ). In summary, results indicate that Sentinel-2 and Landsat 8 satellite data have sufficient spatio-temporal resolution for detecting the phenological characteristics of crop growth in this type of fields (fig. $3 \&$ table 3 ).

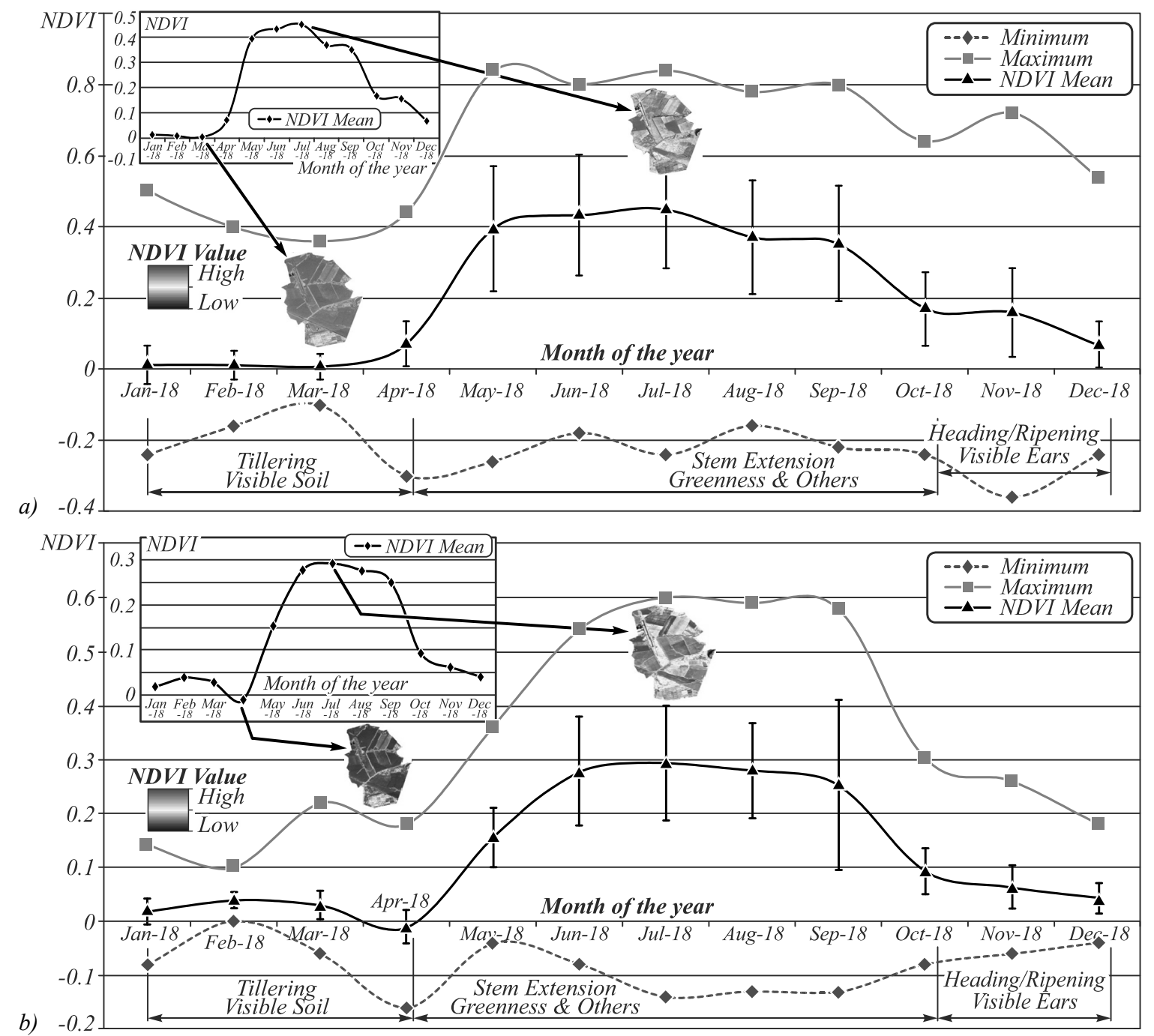

Fig. 3. Crop phenology graph and table based on (a) Sentinel \& (b) Landsat data in the study area with minimum, maximum, mean and standard deviation of NDVI values

Table. 3. Crop phenology table based on (a) Sentinel \& (b) Landsat data in the study area with minimum, maximum, mean and standard deviation of NDVI values

\begin{tabular}{|c|c|c|c|c|c|c|c|c|c|c|c|c|c|}
\hline & NDVI S & Jan-18 & Feb-18 & Mar-18 & Apr-18 & May-18 & Jun-18 & Jul-18 & Aug-18 & Sep-18 & Oct-18 & Nov-18 & Dec-18 \\
\hline \multirow{4}{*}{ A } & Minimum & -0.24 & -0.16 & -0.10 & -0.30 & -0.26 & -0.18 & -0.24 & -0.16 & -0.22 & -0.24 & -0.36 & -0.24 \\
\hline & Maximum & 0.50 & 0.40 & 0.36 & 0.44 & 0.84 & 0.80 & 0.84 & 0.78 & 0.8 & 0.64 & 0.72 & 0.54 \\
\hline & Mean & 0.01 & 0.01 & 0.01 & 0.07 & 0.40 & 0.43 & 0.45 & 0.37 & 0.35 & 0.17 & 0.16 & 0.07 \\
\hline & StD & 0.05 & 0.04 & 0.03 & 0.06 & 0.18 & 0.17 & 0.17 & 0.16 & 0.16 & 0.10 & 0.12 & 0.06 \\
\hline \multirow{4}{*}{ B } & Minimum & -0.08 & 0 & -0.06 & -0.16 & -0.04 & -0.08 & -0.14 & -0.13 & -0.13 & -0.08 & -0.06 & -0.04 \\
\hline & Maximum & 0.14 & 0.10 & 0.22 & 0.18 & 0.36 & 0.54 & 0.60 & 0.59 & 0.58 & 0.30 & 0.26 & 0.18 \\
\hline & Mean & 0.02 & 0.04 & 0.03 & -0.01 & 0.15 & 0.28 & 0.29 & 0.28 & 0.25 & 0.09 & 0.06 & 0.04 \\
\hline & StD & 0.02 & 0.01 & 0.03 & 0.03 & 0.06 & 0.10 & 0.11 & 0.09 & 0.16 & 0.04 & 0.04 & 0.03 \\
\hline
\end{tabular}


Results also indicate the date of season start/end (April/October) tillage and harvest, date of medial season (May, June, July) with peak maturity in July and duration of seasonal length (April to October). NDVI time series results indicate critical growth period or phenology of crop growth in Samara airport area, Russia (fig. 3. \& table. 3). It is representing the local agricultural activities arrangements, crop development phases and weather effect in the study area (fig. 3. \& table. 3). As Russia is the country of very high snow fall which start in the end of October and finish in beginning of April so people start farming in beginning of April and harvest till October.
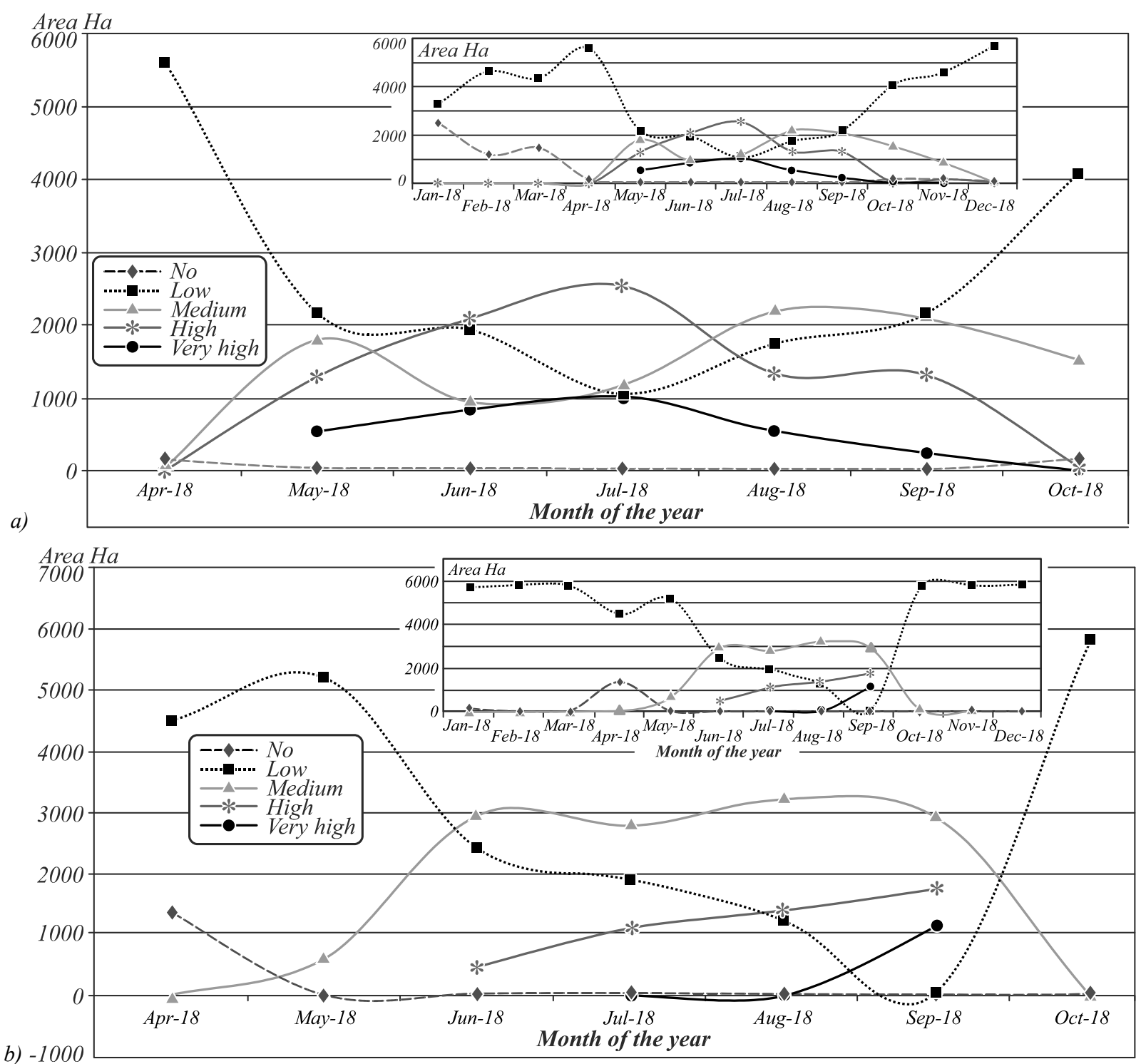

Fig. 4. Cropland area change graph based on NDVI values, (a) Sentinel \& (b) Landsat data

\subsection{Cropland area based on NDVI values}

We also calculate the total cropland area based on NDVI values and for that first, we classify NDVI values according to table. 5 .

As crop calendar and NDVI time series based crop phenology were shown that from January to March and November-December, the whole study area covered by ice due to high snowfall so during this period maximum agriculture area comes under "no agriculture" class (fig. 4 $\&$ table. 4). From April to October we find all NDVI values or classes (table. 5), during this time no and low agriculture classes reduce dramatically and high NDVI value (medium, high \& very high) class's area increased (fig. 4), which also illustration weather effect in the area. With these results, we can say that climate effect on the area as during snowfall there is no vegetation and in peak hot weather around July find highest NDVI values means fully mature crop. Before the beginning of snowfall at the beginning of November, all crops were harvested and later on the area covered by snow so there was no vegetation. In winter session (December to April) we find No to high NDVI classes' area but in the summer session (May to November) we find very high NDVI class with its highest in July which has 1021.37 hectare area of the study area (fig. $4 \&$ table 4 ). 
Table. 4. Cropland area change table based on NDVI values, (A) Sentinel \& (B) Landsat data

\begin{tabular}{|c|c|c|c|c|c|c|c|c|c|c|c|c|}
\hline \multirow{2}{*}{ NDVI_S } & $n-18$ & eb-18 & Iar-18 & Apr-18 & May-18 & Jun-18 & Jul-18 & Aug-18 & Sep-18 & )ct-18 & Nov-18 & Dec-18 \\
\hline & \multicolumn{12}{|c|}{$\mathrm{A}$} \\
\hline$\overline{\text { No }}$ & 37.63 & 1203.17 & 73.93 & 52.50 & 2.45 & 29.17 & 33.54 & 17.32 & 18.45 & 70.53 & 178.09 & $\overline{100.32}$ \\
\hline Low & 92.80 & 4635.5 & 4366.52 & 603.98 & 160.42 & 937.12 & 59.35 & 749.99 & 172.18 & & & 681.13 \\
\hline Medi & 11.84 & 4.37 & 2.50 & 86.36 & 5.81 & & 92 & & 37 & 153 & & 57.53 \\
\hline & 0.78 & 0.01 & 0.10 & 0.21 & & 0 & & & & & & 4.07 \\
\hline & & & & & & & & & & 0.71 & 9.77 & \\
\hline \multirow[t]{2}{*}{ Tota } & 43.05 & 5843.05 & 5843.05 & 5843.05 & 5843.05 & 5843.05 & 5843.05 & 5843.05 & 5843.05 & 5843.05 & 843.05 & 5843.05 \\
\hline & \\
\hline Jo & 9.77 & 20.00 & 95 & 9.62 & & & 43 & & 5.58 & 22.59 & 83 & 19.89 \\
\hline & 04.56 & 5824.33 & 5821.20 & 83.71 & 5208.03 & 240 & & & 52.29 & 5808.33 & 5811.12 & 5824.44 \\
\hline & & & 0.18 & 1.00 & 621.99 & 2948.31 & 2788.38 & 3215.43 & 2899.71 & 13.41 & 7.38 & \\
\hline & & & & & & 468.00 & 1121.49 & 1375.93 & 1751.67 & & & \\
\hline & & & & & & & 0.45 & 1.00 & 1135.08 & & & \\
\hline Total & 44.33 & 5844.33 & 5844.33 & 5844.33 & 5844.33 & 5844.33 & 5844.33 & 5844.33 & 5844.33 & 5844.33 & 5844.33 & 5844.33 \\
\hline
\end{tabular}

Table. 5. NDVI classification

\begin{tabular}{cc}
\hline NDVI classes & Agriculture condition/health \\
\hline$<0.0$ & No agriculture \\
$0.0-0.2$ & Low agriculture \\
$0.2-0.4$ & Medium agriculture \\
$0.4-0.6$ & High agriculture \\
$>0.6$ & Very high agriculture \\
\hline
\end{tabular}

We can visually identify NDVI time-series changes in monthly NDVI maps generated by Sentinel 2B and Landsat data in figure 5. In NDVI maps (fig. 5), dark green color represents crop greenness or health of the crop, where dark brown color is indicator of non-vegetation or water and from brown to green is in-between situation (fig. 5). In Russia, sometimes crop field leaves barren to improve soil fertility for the next crop. That's why in peak summer session some field looks in brown. NDVI maps also show man-made (close to the airport) and natural climate effects on crop phenology as crop growth heavily influenced by management practices such as sowing dates, irrigation, and fertilizer application. These influenced patterns variate from year to year as well as monthly and these changes might impact the canonical temporal profile of the study area crops. It is representing the local agricultural activities arrangement and crop development phases within the study area. In figure 5 all these things can easily identify at individual crop field level with their edge. The spatial crop phenology characterization could provide a supplementary mean for conventional agro-meteorology observation. Subtle shifts in the timing of crop phenology revealed inter/intra annual variation of crop growth and that can be an indicator for variation of climate, cropping system shift and agricultural activities arrangements.

\subsection{Accuracy assessment}

Ground Control Points (GCP) were collect during the fieldwork for accuracy assessment and georeferenced the data [21]. Used google earth for accuracy assessment as it has very high-resolution imageries with photographs. To validate the resultant classified map, accuracy assessment has been done with collected GPS points of crops and calculated user accuracy, producer accuracy, overall accuracy and Kappa coefficient for Sentinel 2B and Landsat OLI data. The overall accuracy for the crop phenology mapping and monitoring was $92 \%$ with $92 \%$ Kappa (table 6).

Table 6. Accuracy assessment based of field verification

\begin{tabular}{lrrrrr}
\hline \multicolumn{1}{c}{ Class } & $\begin{array}{c}\text { Agricul- Non-Agri- } \\
\text { ture }\end{array}$ & $\begin{array}{c}\text { culture } \\
\text { culners }\end{array}$ & Total & $\begin{array}{c}\text { User } \\
\text { accuracy }\end{array}$ \\
\hline Agriculture & 35 & 2 & 1 & 38 & 0.921 \\
Non-Agri- & 3 & 31 & 1 & 35 & 0.885 \\
$\quad$ culture & 0 & 1 & 26 & 27 & 0.962 \\
Others & 38 & 34 & 28 & 100 & \\
$\quad$ Total & & & & \\
$\quad$ Producer & 0.921 & 0.911 & 0.928 & & \\
$\quad$ accuracy & & & & & \\
$\quad \begin{array}{l}\text { Overall } \\
\quad \text { accuracy }\end{array}$ & 0.920 & & & & \\
Kappa & 0.920 & & & & \\
\hline
\end{tabular}

When we compare Sentinel and Landsat data results for crop growth from beginning to end, both data show positive relationship but Sentinel 2B data have little bit higher accuracy in terms of significant, a fraction of the variance in phenological timing/dates than Landsat data. In tillering or visible soil stage Sentinel data show continuous increasing NDVI values but Landsat data results show low NDVI values in April compared to February-March. When we compare all NDVI classes from "No to Very High Agriculture" classes, Sentinel data show all classes from May to November but Landsat shows all classes only from July to September which represents that Sentinel 2B data generated NDVI values are more accurate and qualitative in compare of Landsat data [22]. We confirm these results during field visit for all crop growth stage (fig. 6).

\section{Discussion}

Although additional data from more ecological stations and cultivars are needed to validate the presented results in the future work, this study could be useful for assessing crop phenology over large agricultural lands using satellite imagery given that the NDVI data could be acquired by more high-resolution satellite data. The method in this study would also provide a useful reference for further studies on other crops or vegetation species. The findings from the one-year consecutive experi- 


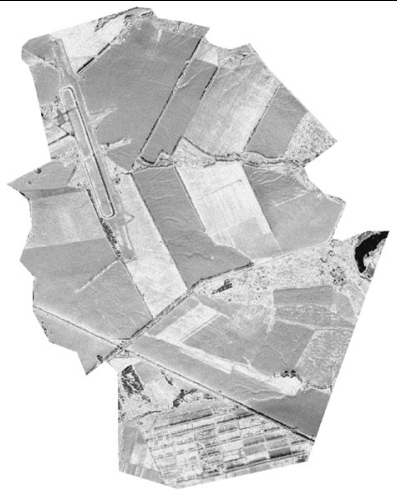

Sentinel_01/2018

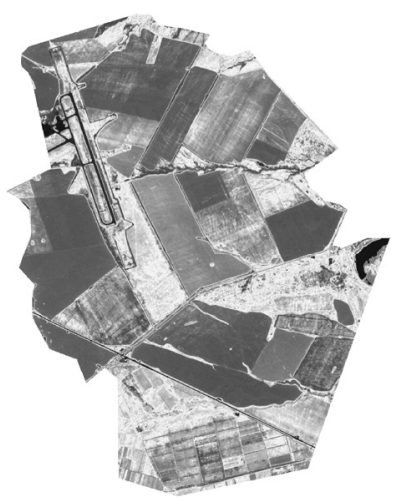

Sentinel_05/2018

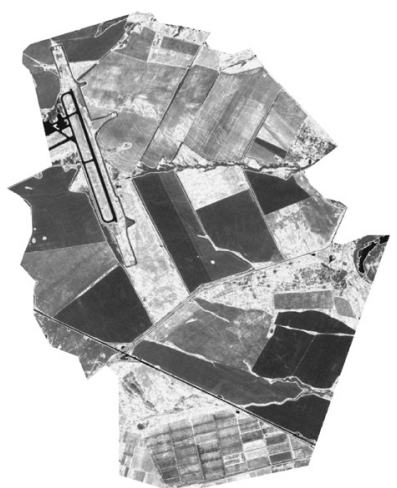

Sentinel_09/2018

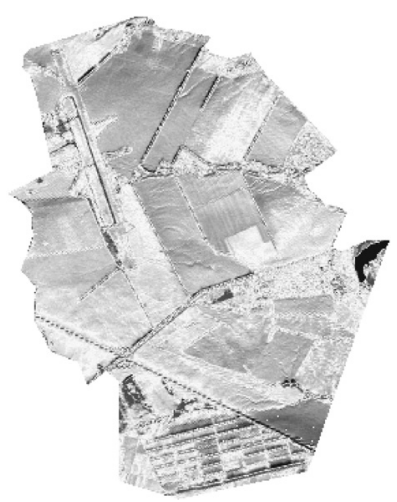

Landsat_01/2018

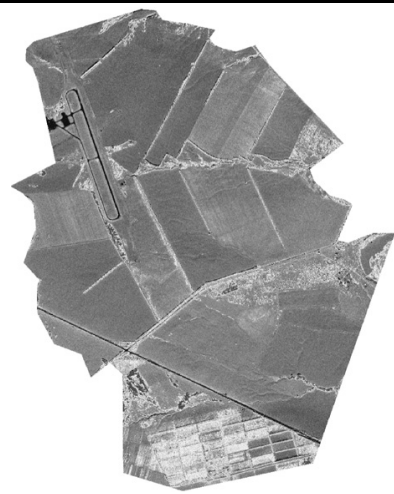

Sentinel 02/2018

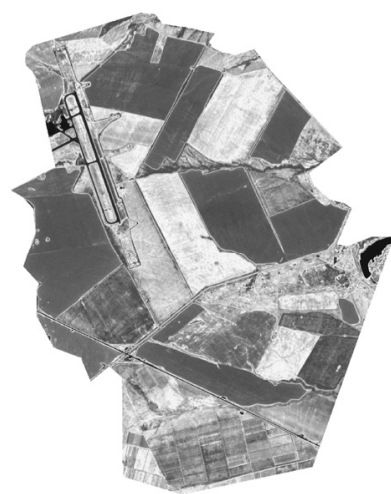

Sentinel_06/2018

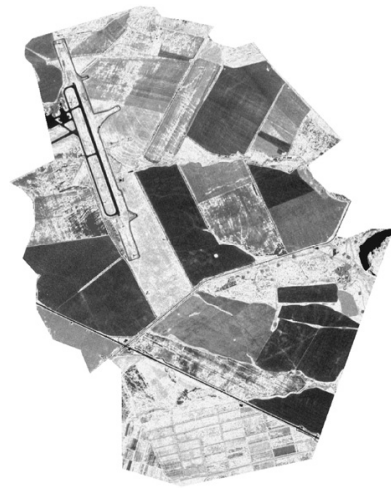

Sentinel_10/2018

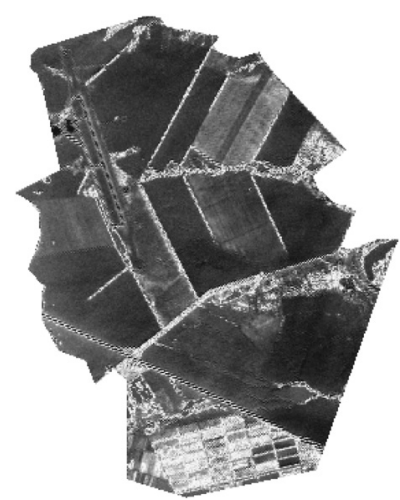

Landsat_02/2018

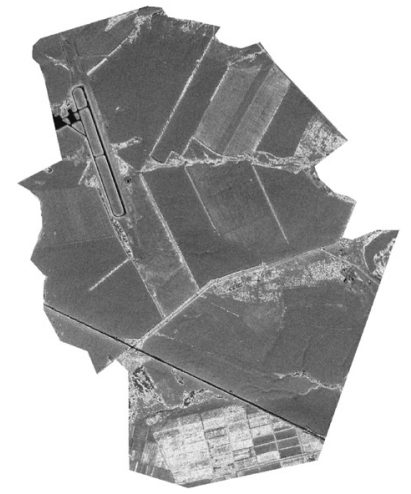

Sentinel 03/2018

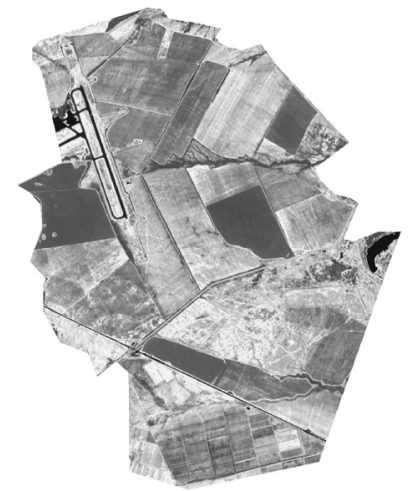

Sentinel_07/2018

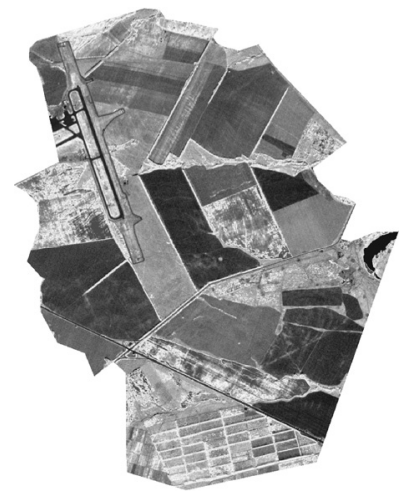

Sentinel_11/2018

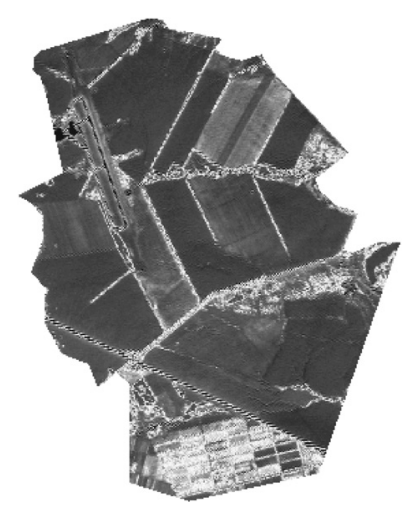

Landsat_03/2018

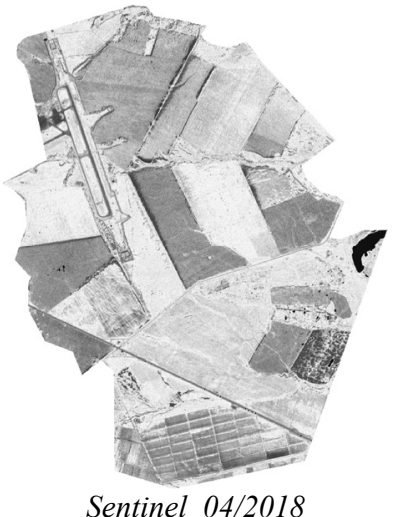

Sentinel 04/2018

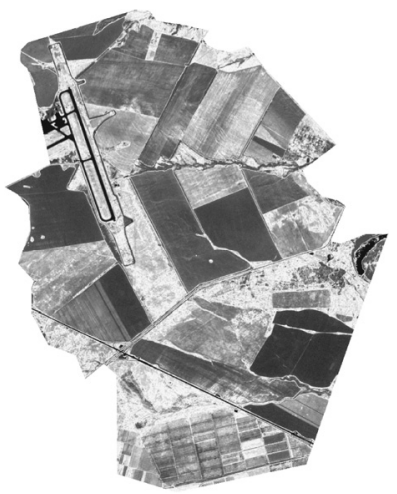

Sentinel_08/2018

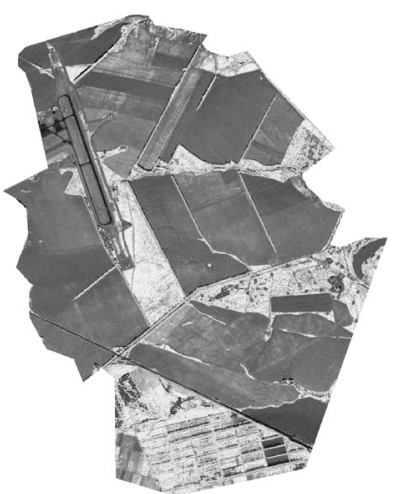

Sentinel_12/2018

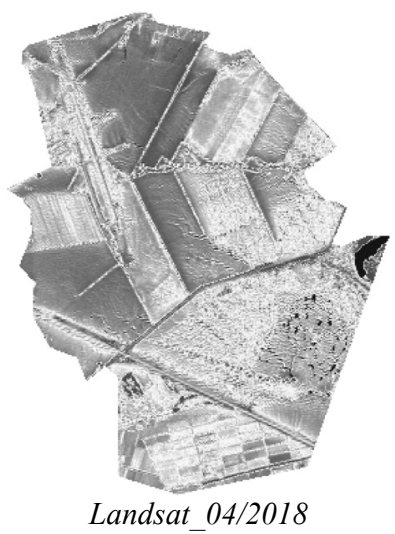

Fig. 5. NDVI time series maps

NDVI
Value 


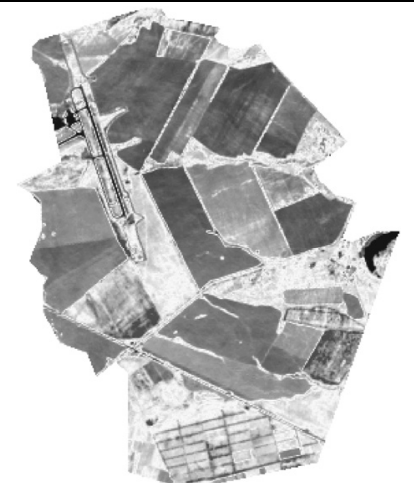

Landsat $05 / 2018$

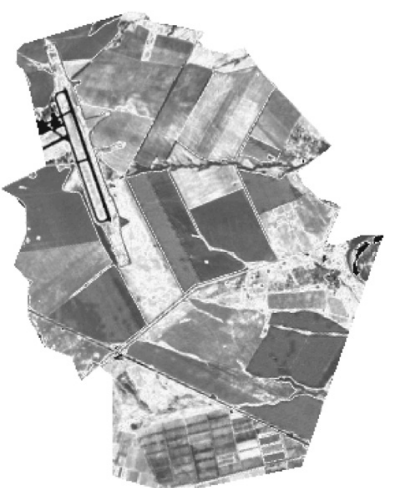

Landsat_09/2018

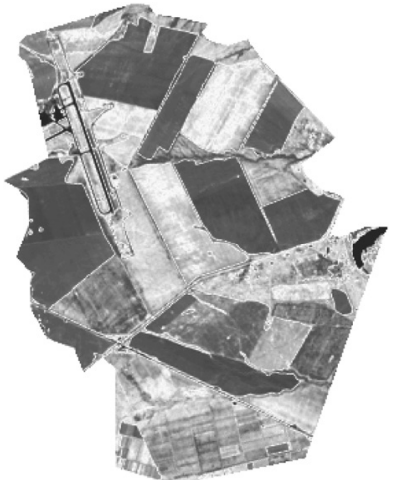

Landsat 06/2018

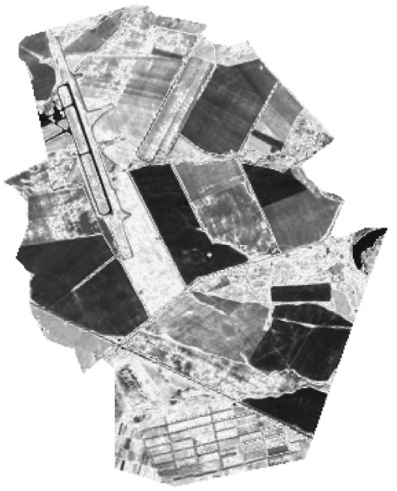

Landsat_10/2018

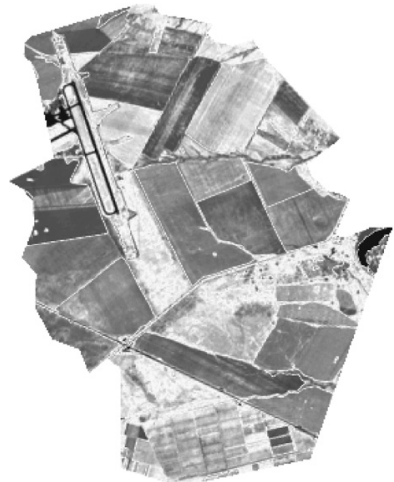

Landsat_07/2018

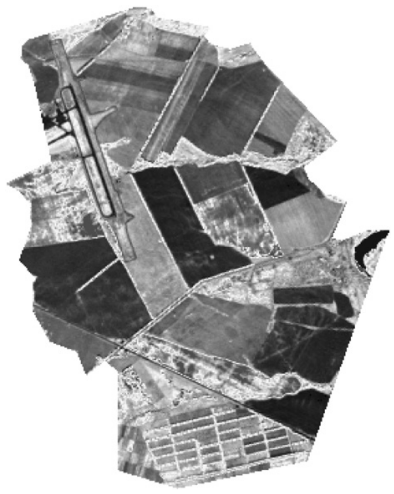

Landsat_11/2018

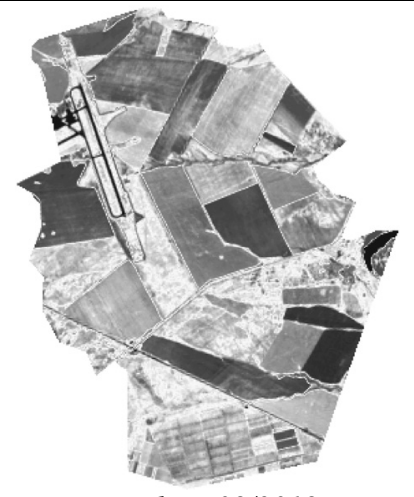

Landsat $08 / 2018$

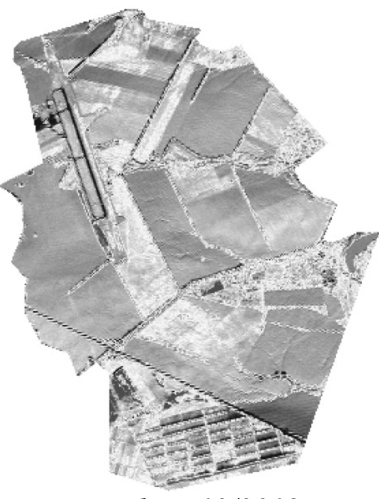

Landsat_12/2018
Continuation of Fig. 5
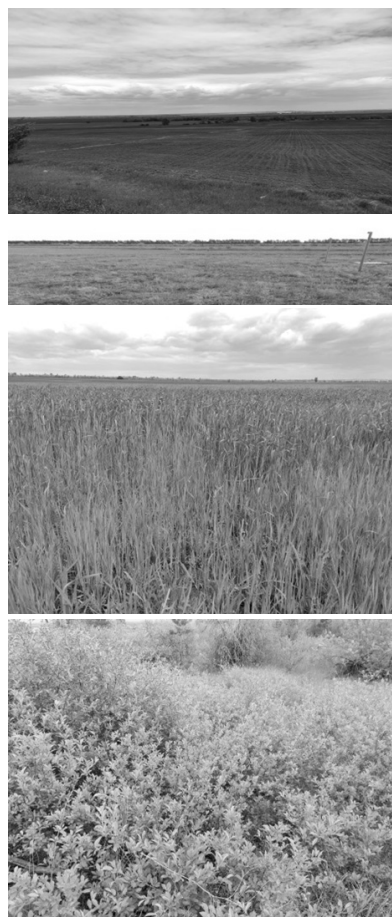

Fig. 6. Field photographs

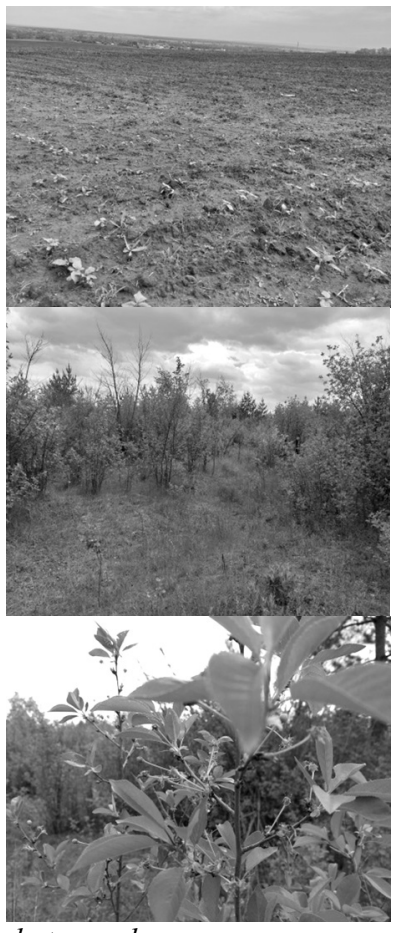

The future work is directed to the incorporation of NDVI an operational system for continuous monitoring of crop phenology. Besides, new spectral indices with optimized wavelengths from ASD hyperspectral data will be exploited for crop phenology detection shortly [23].
Although the cropping area presents unique phenological trajectory in the NDVI time-series, the summer crop has a synchronized growth stage with other vegetation, making it difficult to be distinguished; crop growth status or cultivation management might be different among different farmlands that eventually influence the NDVI value; and the availability of labor and farming machineries which are highly dependent on agricultural scheduling when sowing and harvesting comes. All these factors are also a critical influence on other areas and sessional crops.

Our study presents the first large-scale implementation of a flexible protocol to monitor and mapping crop growth development and damage with limited technical skills. Our results show that satellite remote sensing with groundtruthing or fieldwork can capture sufficient information about different crop growth stages or vegetation greenness for crop phenology during crop development than other convention methods with higher accuracy.

\section{Conclusions}

Crop growth was monitored and mapped by NDVI time series derived from Sentinel-2B and Landsat OLI data with ground-truthing. The results indicate that NDVI values were variate according to the crop calendar which also affected by the weather. NDVI can be used to detect the dates of active tillering, middle heading and maturity. It can be concluded that mapping crops through satellite remote sensing data by exploring phenological patterns is 
an efficient, reliable and traceable technique compared to other conventional methods. The dates of active tillering, jointing and maturity could be useful for irrigation management, fertilization recommendation, and harvesting determination, respectively. This demonstrates that reasonable accurate maps of crop phenology can be generated from the Sentinel-2B and Landsat OLI time series, which provides a novel insight for data assimilation in the field of crop growth simulation. Consequently, this approach is well suited to be transferred to other regions or countries to a relevant nation to an international level organization to make benefits and fulfill agriculture application requirements from remote sensing data based time series.

\section{References}

[1] Boori MS, Choudhary K, Kupriyanov A, Kovelskiy V. Satellite data for Singapore, Manila and Kuala Lumpur city growth analysis. Data in Brief 2016; 7: 1576-1583. DOI: 10.1016/j.dib.2016.04.028.

[2] Griffiths P, Nendel C, Hostert P. Intra-annual reflectance composites from Sentinel-2 and Landsat for national-scale crop and land cover mapping. Remote Sensing of Environment 2019; 220: 135-151.

[3] Boori MS, Choudhary K, Kupriyanov A, Sugimoto A, Evers M. Natural and environmental vulnerability analysis through remote sensing and GIS techniques: A case study of Indigirka River basin, Eastern Siberia, Russia. Proc SPIE 2016; 10005: 100050U. DOI: 10.1117/12.2240917.

[4] Becker-Reshef I, Justice C, Sullivan M, Vermote E, Tucker C, Anyamba A, Small J, Pak E, Masuoka E, Schmaltz J, Hansen M, Pittman K, Birkett C, Williams D, Reynolds C, Doorn B. Monitoring global croplands with coarse resolution earth observations: the global agriculture monitoring (GLAM) project. Remote Sens 2010; 2: 1589-1609.

[5] Lebourgeois V, Dupuy S, Vintrou E, Ameline M, Butler S, Bégué A. A combined random forest and OBIA classification scheme for mapping smallholder agriculture at different nomenclature levels using multisource data (simulated Sentinel-2 time series, VHRS and DEM). Remote Sens 2017; 9: 259.

[6] Skakun S, Franch B, Vermote E, Roger JC, Justice C, Masek J, Murphy E. Winter wheat yield assessment using Landsat 8 and Sentinel-2 data. IEEE International Geoscience and Remote Sensing Symposium (IGARSS) 2018; 5964-5967.

[7] Matton N, Canto GS, Waldner F, Valero S, Morin D, Inglada J, Arias M, Bontemps S, Koetz B, Defourny P. An automated method for annual cropland mapping along the season for various globally-distributed agrosystems using high spatial and temporal resolution time series. Remote Sens 2015; 7: 13208-13232.

[8] Hufkens K, Melaas EK, Foster T, Ceballos F, Robles M, Kramer B. Monitoring crop phenology using a smartphone based near-surface remote sensing approach. Agricultural and Forest Meteorology 2019; 265: 327-337.
[9] Wang Y, Xue Z, Chen J. Spatio-temporal analysis of phenology in Yangtze River Delta based on MODIS NDVI time series from 2001 to 2015. Front Earth Sci 2019; 13(1): 92-110. DOI: 10.1007/s11707-018-0713-0.

[10] Jin X, Kumar L, Li Z, Feng H, Xu X, Yang G, Wang J. A review of data assimilation of remote sensing and crop models. Eur J Agron 2018; 92: 141-152.

[11] Sakamoto T, Yokozawa M, Toritani H, Shibayama M, Ishitsuka N, Ohno H. A crop phenology detection method using time-series MODIS data. Remote Sens Environ 2005; 96: 366-374

[12] Zheng H, Cheng T, Yao X, Deng X, Tian Y, Cao W, Zhu $Y$. Detection of rice phenology through time series analysis of ground-based spectral index data. Field Crops Res 2016; 198: 131-139.

[13] Manuel CT, Haro FJG, Busetto L, Luigi R, Beatriz M, Gilabert MA, Gustau CV, Fernando C, Mirco B. A critical comparison of remote sensing leaf area index estimates over rice-cultivated areas: From Sentinel-2 and Landsat$7 / 8$ to MODIS, GEOV1 and EUMETSAT Polar system. Remote Sens 2018; 0(5): 763.

[14] Liu S, Li Q, Mao X, Zhang J. Evaluation on consistency between HJ-1 CCDand TM images in monitoring fractional green vegetation cover. International Geoscience and Remote Sensing Symposium (IGARSS) 2011: 1005-1008. DOI: 10.1109/IGARSS.2011.6049303.

[15] Li Q, Wang C, Zhang B, Lu L. Object-based crop classification with Landsat-MODIS enhanced time-series data. Remote Sens 2015; 7(12): 16091-16107.

[16] Boori MS, Choudhary K, Kupriyanov A, Kovelskiy V. Urbanization data of Samara City, Russia. Data in Brief 2016; 6: 885-889. DOI: 10.1016/j.dib.2016.01.056.

[17] Kundu A, Patel NR, Saha SK, Dutta D. Desertification in western Rajasthan (India): an assessment using remote sensing derived rain-use efficiency and residual trend methods. Natural Hazards 2017, 86: 297-313.

[18] Patel NR, Yadav K. Monitoring spatio-temporal pattern of drought stress using integrated drought index over Bundelkhand region, India. Natural Hazards 2015, 77: 663-677.

[19] Earth observatory NASA. Source: $\langle\mathrm{http}: / /$ earthobservatory.nasa.gov/Features/MeasuringVeget ation/ $>$.

[20] Congalton RG, Green K. Assessing the accuracy of remotely sensed data: Principles and practices. $2^{\text {nd }}$ ed. Boca Raton: Lewis Publishers; 2009.

[21] Justice CO, Townshend JRG, Holben BN, Tucker CJ. Analysis of the phenology of global vegetation using meteorological satellite data. Int J Remote Sens 1985, 6: 1271-1318.

[22] Leff B, Ramankutty N, Foley JA. Geographic distribution of major crops across the world. Global Biogeochem Cycles 2004; 18: GB1009.

[23] World population prospects: The 2015 revision. In Book: Population division of the department of economic and social affairs of the United Nations Secretariat. New York: Department of Economic and Social Affairs; 2015.

\section{Authors' information}

Mukesh Singh Boori (b. 1980) is Senior Scientist in Samara University Russia and Adjunct Professor in American Sentinel University Colorado USA. Currently he is involved in remote sensing and GIS teaching and Russian academic excellence project. He has also held positions at University of Rennes 2 France, University of Bonn Germany, Hokkaido University Japan, Palacky University Czech Republic, Ruhr University Bochum Germany, Leicester University UK, NOAA/NASA USA, JECRC University, JKLU University, MDS University and JSAC/ISRO India. He hold Postdoc from University of Maryland USA, PhD from Federal University - RN (UFRN) Brazil, Predoc from Katholiek Univer- 
sity Leuven Belgium, MSc from MDS University and BSc from University of Rajasthan India. He received several distinguish awards including national academy of sciences (NAS) fellowship through national research council (NRC) central government of USA Washington DC, European union social fund, Honorary fellow University of Leicester UK, Prestigious Brazil-Italy government fellowship, Belgian and Indian government space fellowship. He published 100+ peer-reviewed papers including books as a first author in the field of earth and space science and his prime research interest is satellite earth observations through remote sensing \& GIS technology. He is a member of many scientific societies / journals / committees, led a number of projects, organized a number of conferences, delivered conference opening ceremony speech, keynote speaker, plenary session talk, invited talk, chaired sessions and visited 22 countries as official trips. E-mail: boori.m@ssau.ru.

Komal Choudhary is scientist in Samara University, Russia (09/2015 to present) as well as PhD student in The Hong Kong Polytechnic University, Hong Kong (09/2018 to present). She has completed her Bachelors and Master's degree in Geography from University of Rajasthan, India in the year 2003 and 2005 respectively. She also completed Bachelors of Education in 2007 from University of Rajasthan, India. She has more than 50 International Publications including Books on Vulnerability, Risk Assessment and Climate Change. Her prime research interest is "Sustainable Development Studies through Multi-Criteria Approach". After her education she was a college level lecturer in Indian college and she has to her credit an illustrious experience in teaching and other administrative responsibilities spanning over a decade and has served in various capacities like Principal, Faculty Development and Controller of Examinations. Komal brings with herself a vast experience in curriculum design, research guidance and innovative teaching. She visited Brazil, USA, Europe, Russia, India and Hong Kong. E-mail: komal.kumari@,connect.polyu.hk.

Alexander Victorovich Kupriyanov (born 1978) graduated with honors from Samara State Aerospace University (SSAU) (2001). Candidate's degree in Technical Sciences (2004) and Doctor of Engineering Science (2013). Currently, Senior Researcher at the Image Processing Systems Institute, Russian Academy of Sciences, and part-time position as Associate Professor at SSAU's sub-department of Technical Cybernetics. Areas of interest: digital signals and image processing, pattern recognition and artificial intelligence, nanoscale image analysis and understanding, biomedical imaging and analysis. More than 90 scientific papers, including 42 published articles and 2 monographs.

E-mail: akupr@ssau.ru.

Received September 16, 2019. The final version - February 27, 2020. 